\title{
NATURALEZA Y REPRESENTACIÓN EN LA POESÍA DE MIGUEL ÁNGEL VELASCO
}

\author{
NATURE AND REPRESENTATION IN \\ MIGUEL ÁNGEL VELASCO'S POETRY
}

\author{
Samuel del Valle Gómez \\ Universitat de les Illes Balears
}

Resumen: Este trabajo explora el tratamiento de la naturaleza en la poesía de Miguel Ángel Velasco, centrándose para ello en ejemplos extraídos de dos de sus obras: El dibujo de la savia y La miel salvaje. Su principal propósito es constatar la importancia del fenómeno natural en Velasco y analizar su evolución: desde la descripción de pequeños objetos naturales de El dibujo de la savia hasta la poética de las correspondencias de algunos poemas de La miel salvaje.

Palabras Clave: Miguel Ángel Velasco; naturaleza; poéticas del siglo xx.

Aвstract:This paper explores the treatment of nature in Miguel ÁngelVelasco's poetry, focusing for this purpose on examples which have been selected from among two of his works: El dibujo de la savia and La miel salvaje. Its main purpose is to contrast the significance of natural phenomena in Velasco's production and to analyse its evolution: from the description of small natural objects in El dibujo de la savia to the poetics of correspondences of some poems belonging to $\mathrm{La}$ miel salvaje.

KEY-WORDs: Miguel Ángel Velasco; nature; 20th century poetry. 
El caso del poeta Miguel Ángel Velasco es uno de los que con mayor elocuencia representa la incierta suerte a la que se expone la obra literaria de los autores de nuestro tiempo, sujeta siempre a tantos factores como podamos imaginar, muchos de ellos completamente dependientes del más puro azar y, sobre todo, ajenos a lo que filológicamente debería primar: la calidad de los textos. Miguel Ángel Velasco, nacido en Palma de Mallorca (1963), lugar también de su prematuro fallecimiento (2010), escribió más de una docena de libros de poesía desde sus precoces inicios literarios hasta la publicación de su última obra, pocos meses antes de su muerte. Algunos de estos, además, pueden considerarse piezas imprescindibles dentro de la poesía de su generación. Pese a ello, su obra permanece prácticamente desconocida para el gran público, a lo que ha de agregarse la escasísima atención que ha suscitado hasta el momento en el ámbito académico ${ }^{1}$.

Tempranamente iniciado en los placeres de la poesía por su pa$\mathrm{dre}^{2}$, un Velasco aún adolescente comienza a escribir sus primeros versos y a ser distinguido con premios que lo sitúan como firme promesa del panorama poético español. Su primer libro, Sobre el silencio y otros llantos, se hace con el accésit del Premio Adonáis, en el año 1979. Dos años después, es su obra Las berlinas del sueño la que se alza con el primer puesto. Por entonces, Velasco es un estudiante de voraz apetito lector que escribe versos de raigambre surrealista

1 Prácticamente solo contamos con dos trabajos académicos que estén dedicados por completo a su figura. Por un lado, el artículo «Tradición clásica y culturalismo en la poesía de Miguel Ángel Velasco» (Díaz de Castro, 2011), exhaustivo trabajo que explora las referencias culturalistas de toda la obra del poeta, desde los primeros poemarios de corte surrealista hasta su último libro, Ánima de cañón. Y, por otro, el estudio introductorio a la antología La mirada sin dueño, titulado «Una ética del exceso. La poesía de Miguel Ángel Velasco» (Gallego, 2008).

2 «Desfallecer», uno de los poemas de La vida desatada que se centra en la figura del padre fallecido, incluye unos versos que atestiguan la importancia de Miguel Pons Camps, de profesión maestro, en los años de formación lectora del poeta: «O allí en Sa Foradada, conmigo, en aquel tiempo / en que me comenzabas a leer / a Manrique y Machado, pues tú fuiste / el que me despertara a la emoción / de las palabras, cuando, / con tu voz grave y queda, ibas diciendo: / ¿Y ha de morir contigo el mundo mago?» (Velasco, 2000: 72). 
firmados como MiguelVelasco y que destaca entre sus compañeros de clase por su llamativa y bohemia vestimenta, que lo presenta ante el mundo como una suerte de dandy finisecular actualizado (Llop, 2010; Legorburu, 2011: 13). No es de extrañar, pues, que sus modelos literarios en ese tiempo sean esencialmente los simbolistas franceses y que declare sin ambages su concepción únicamente estética del hecho poético ${ }^{3}$. En ese sentido, el rasgo que substancia en mayor medida la poética del primerVelasco es el irracionalismo, propiciando que algunos autores hablen de un «surrealismo estetizante» (Llop, 2010), o de un intento de «revitalizar la lección del surrealismo» (Prieto de Paula, 2008), para referirse al breve espacio de tiempo en que varios poemarios de signo surrealista, fundamentalmente De una niña de provincias que se vino a vivir en un Chagall, de Blanca Andreu, los dos primeros títulos de Velasco y algunas obras surgidas en la estela de las de estos dos autores, pudieron dar la impresión fugaz de que se iba a engendrar una corriente neosurrealista sucesora generacionalmente de los novísimos, hipótesis que vino a desbaratar, casi a un tiempo, la irrupción de la poesía de la experiencia en el panorama literario y su consecuente constitución en corriente hegemónica de la poesía española de los años ochenta y noventa.

Así pues, las características más notables de este inicial Velasco, que no solo cubre el período que abarca los dos libros premiados, sino que se extiende al posterior y menos difundido Pericoloso sporgersi (1985), son aquellas de inspiración inequívocamente surrealista, un surrealismo que por su opacidad, su dificultosa penetración, se asemeja mucho más a las fuentes francesas que al llamado «surrealismo a la española» ${ }^{4}$.

3 En una entrevista concedida al periódico $A B C$ tras ganar el Premio Adonáis, precisamente subtitulada "Al Adonáis le gustan los simbolistas», dice así: «Los autores simbolistas me han cautivado, en especial Coleridge, Nerval, hasta Borges»; a lo que más tarde añade: «Para mí la poesía es una recreación artística y nada más. No suscribo aquello de que la poesía es un arma cargada de futuro, precisamente por asociarla a su autor, Celaya. El futuro no se hace con la poesía: hay unos mítines y elecciones para hacer el futuro» (en Sebastián, 1981).

4 Así lo expresa Díaz de Castro: «Como poeta surrealista está cerca de la fuente francesa. No hay apenas nada de lo que el surrealismo español de la postguerra aportó: ni la corrosiva experiencia lingüística de un Labordeta desmixtificador y cotidiano, ni tremendismo, ni la burla procaz de los postistas ni tampoco el juego etéreo de los más integrados en su papel de vanguardistas del franquismo» (Díaz de Castro, 1984: s. p.) 
Tras esta primeriza aunque prometedora etapa, tendrá que pasar una década entera hasta que nuestro poeta dé a la imprenta el siguiente título de su obra, El sermón del fresno, libro completamente rupturista con respecto a los precedentes. Durante todo ese tiempo la poética de Velasco se desprende de los visajes y trucos surrealistas, del verbalismo y el irracionalismo anteriores, y pasa a fundarse en una mirada reflexiva, que aspira a la comunicación a través del poema descreyendo de los presupuestos vanguardistas que deja atrás 5 . En esta búsqueda de una voz clara juegan un papel decisivo el magisterio y la amistad de Agustín García Calvo e Isabel Escudero, el primero de los cuales es el máximo responsable de que incorpore a sus poemas la música de los metros tradicionales (Díaz de Castro, 2011:36). Esta asunción de las formas clásicas, la «busca de un verso riguroso" (ibíd.), es uno de los elementos de mayor importancia en la configuración de la nueva poética, junto con la entrada de los dos grandes temas que van a presidir su poesía posterior: la muerte y, de modo más tímido, la naturaleza.

Es en la siguiente entrega poética, El dibujo de la savia (1998), cuando la naturaleza se convierte en el espacio de referencialidad dominante, expresada fundamentalmente con el espléndido uso de la figuración metafórica de que se sirve Velasco. La experiencia psicodélica del poeta con las substancias enteogénicas modela su mirada en un viaje de exaltación de la percepción sensorial que toma varios caminos: por un lado, la descripción del estado alterado de conciencia que las substancias propician en él; por otro, el nuevo entendimiento con la naturaleza que este proceso le ocasiona. Sin embargo, los poemas de ese segundo camino rehúyen la constatación de la enormidad del medio natural como conjunto; antes bien, descienden a lo objetual, incluso a lo minúsculo, quedando como una de las notas distintivas del poemario su condición de breve catálogo de las pequeñas cosas —o pequeños detalles- del mundo natural. Minuciosidad descriptiva, detención temporal y arrobo visionario son algunas de las características que se funden en este libro con intención de cantar la maravilla del mundo, características que se extienden a las siguientes obras del poeta. Velasco con su antigua poética, que lo lleva al extremo de omitir los títulos de sus primeros libros en algunas de las contracubiertas de los nuevos poemarios, presumiblemente redactadas o guiadas por él (Díaz de Castro, 2011: 36). 
Dejando a un lado La vida desatada (2000), que retoma la temática más elegíaca de El sermón del fresno (la reflexión sobre la muerte a partir de la pérdida del padre y, en algún caso, del abuelo), incluyendo asimismo nueve composiciones del mismo libro entre sus páginas y descansando a menudo sobre motivos realistas, hasta cierto punto cercanos a la poesía experiencial, todo el desarrollo posterior de la obra de Miguel Ángel Velasco tendrá la naturaleza como uno de los temas nucleares, aunque sin descuidar nunca el tema primordial de la muerte. Desde La miel salvaje (2003), una de las obras más redondas de su carrera, que le vale el prestigioso premio Loewe y la atención de la crítica especializada, hasta los tres libros posteriores, Fuego de rueda (2006), Memoria del trasluz (2008) y Ánima de cañón (2010), la mirada de Velasco, vuelta de nuevo sobre la naturaleza, sobre lo pequeño observado, penetra con idéntico detalle y más profundidad si cabe en los objetos que la componen, pero ahora tratando de extraer en el intento un conjunto de implicaciones de orden cósmico que «reclama la belleza y la armonía» del mundo (Díaz de Castro, 2011: 48). La lectura de la naturaleza como una suerte de entramado de correspondencias («andamiaje secreto» [García Martín, 2003]), revelado por la experiencia enteogénica, configura un mundo afirmativo que cifra el ideal de «belleza» y «armonía» al que el poeta aspira. Para tal propósito, el lenguaje utilizado recupera y perfecciona la fibra de los mejores poemas naturales de El dibujo de la savia, emprendiendo un camino de empoderamiento estilístico que desde La miel salvaje hasta su último libro (Ánima de cañón) descubrirá un dominio de la lengua (en la variedad del léxico, en la creación metafórica, etc.) de dificil parangón en la poesía española de los últimos años.

Como ya se ha dicho, los dos temas más relevantes en la obra de Miguel Ángel Velasco son la muerte y, en un importante segundo lugar, la naturaleza. Nuestra atención aquí se va a dirigir exclusivamente al segundo, en un intento de analizar el fenómeno natural a través de la indagación en la mirada que el poeta proyecta sobre este, para lo cual nos vamos a centrar — con alguna excepción- en dos poemarios de la segunda poética de Velasco, El dibujo de la savia y La miel salvaje.

Sería imposible comenzar satisfactoriamente el itinerario que nos proponemos trazar a través de la poética de Velasco en relación con la naturaleza sin recalar antes en el fenómeno de las substancias enteogénicas, sobre todo por la importancia que estas tienen en 
su aprehensión de la naturaleza desde un renovado punto de vista ${ }^{6}$. Esta importancia puede justificarse por varias razones, dos de ellas de todo punto insoslayables. La primera, menos relevante, se hace evidente en algunas de las composiciones de El dibujo de la savia: casi todos los poemas en que Velasco da cuenta de la experimentación con alucinógenos presentan al sujeto poético rodeado de entornos naturales, algo que, por otro lado, es costumbre en el consumo - experimental, por norma general- de este tipo de drogas alteradoras de la conciencia. La segunda razón, sin embargo, aunque incluye a la anterior, apunta a una dirección aún más crucial. La visión de la naturaleza que Velasco ofrece tras la maduración de las experiencias visionarias se ve inequívocamente afectada por estas, incluso cuando los poemas no explicitan en ningún momento que el mirar del poeta se da a través del filtro que la lente enteogénica dispone. Esto es especialmente ostensible en aquellas composiciones en que Velasco se propone inventariar algunos de los pequeños objetos de la naturaleza que atraen su ebria atención, los cuales aísla con diligente espíritu ensalzador y denodada expresión extática, algo que hemos dado en llamar poema objetual y de lo que nos ocuparemos más adelante. Hablar, pues, de estos poemas sin aludir al despertar de esa nueva mirada que los genera — dada por la experiencia psicodélica — sería un grave error.

Junto a una sensorialidad desatada, primera característica de estos poemas de mirada desmandada, toda la poesía de influencia lisérgica deVelasco (y en esto los poemas objetuales que luego trataremos son el mejor ejemplo) está fuertemente atravesada por el mirar asombrado del que contempla las cosas por primera vez, como reveladas ante una nueva luz y, en cualquier caso, portadoras en su entraña de una honda verdad que alcanza al poeta sin necesidad del intermediario de la razón, de modo fulgurante y luminoso. Así pues, la extrañeza, de repente, ante las cosas, que se presentan como renacidas ante la nueva mirada inquisitiva y límpida del sujeto poético, será clave en el poeta. Un buen ejemplo de ello es «Las nubes», auténtico poema objetual en que, sin embargo, al contrario que en la gran mayoría de estos, el material poético no se centra tanto en la descripción del objeto como en la reflexión que suscita en el sujeto poético saberse

6 Sobre este particular, es imprescindible la consulta de un artículo escrito por el propio Velasco, «La mirada sin dueño» (1993). La alusión a Claudio Rodríguez será utilizada también porVelasco para una de las partes de La miel salvaje, además de ser el título de la antología de su obra preparada porVicente Gallego. 
consciente de una nueva mirada con que descubrir el mundo, que en este caso, ya decimos, se orienta a las nubes:

\author{
Yo no os había visto hasta aquel día, \\ iba bajo vosotras sin saberos, \\ decía acaso nube con descuido \\ o bien cogía una para un verso \\ como pañuelo claro en el andén \\ de la memoria. Pero no os veía. \\ ¿Qué haría mientras tanto; en qué comercio \\ oscuro me andaría con el sueño; \\ en qué mina de olvido, en qué caldera \\ apilaba el carbón de la desdicha; \\ por qué calles sin cielos vagaría \\ mirándome las puntas polvorientas \\ de los tristes zapatos; o con qué \\ visera amarga malogré mis ojos; \\ qué amor avaro los tenía presos \\ en espejos de sed, que no veía \\ las luminosas nubes? (Velasco, 1998: 16).
}

"Yo no os había visto hasta aquel día, / iba bajo vosotras sin saberos», dice Velasco, contraponiendo una mirada rutinaria y, por tanto, superficial de las cosas a un nuevo mirar en que el sujeto trata de aprehender el objeto, traspasándolo, alcanzando su esencia y haciendo que este le devuelva su mirada ${ }^{7}$. El despertar de esta nueva mirada induce a Velasco a apercibirse de la belleza de las cosas. Las nubes son —o, por mejor decir, el descubrimiento de las nubes—, en este caso, las protagonistas del poema. ¿Cómo no había reparado en ellas?, se pregunta de forma original en la parte final del desarrollo. Decía «nube» con descuido; quizá podía utilizarlas ornamentalmente en sus versos - la reflexión es, pues, también metapoética: ajusta cuentas con el uso únicamente estético de las cosas de sus antiguos poemas-; pero no se había detenido a ver la nube en toda su significación, aislada, objetivada, sentida como realidad pura que se nos presentase por vez primera. Esta objetivación, pues, relativa al enfoque aislado y minucioso de los objetos de la naturaleza, es otro de los rasgos que se

7 Dice así la contraportada de El dibujo de la savia: «En su vocación de identificación con el objeto, algunos de estos versos dan cuenta de experiencias con sustancias psiquedélicas, en tanto que propiciadoras de una mirada desprendida, análoga a la de la creación poética, donde las cosas nos devuelven la mirada». 
desencadenan de la mirada visionaria de Velasco, y el que principalmente substancia los poemas objetuales. Todo ello entronca con lo que Gallego ha llamado "penetrar en el doble fondo de las cosas", esto es, la experiencia lisérgica como busca de conocimiento:

Más allá de un intento descriptivo del color y la textura de esa ebriedad, el poeta aprovecha esa apertura radical que la sustancia intoxicante impone a los sentidos para penetrar en el doble fondo de las cosas. El ácido lisérgico es utilizado pues como sacramento, deviene vínculo y vecindad con lo sagrado. [...] Lo que busca Velasco en el seno de la experiencia psiquedélica es conocimiento, un tipo de conocimiento que nada tiene que ver con la percepción rutinaria y que se recibe como pura intensidad, lo mismo que en el arte (Gallego, 2008: 21).

La fórmula por excelencia de que se sirve Velasco para aproximarse al fenómeno natural, ya está dicho, es el poema objetual. Lo que sobre ella vamos a explicar a continuación no podría comprenderse por completo sin lo que hemos apuntado antes, especialmente por lo que toca al nuevo mirar que las substancias psicodélicas activan en el poeta. Cabe decir, pues, que la totalidad de los poemas que agrupamos bajo la etiqueta del poema objetual responden al estímulo de este tipo de substancias.

Como paso previo al análisis de estos poemas, sería pertinente que dedicásemos un breve espacio a justificar la nomenclatura que hemos escogido. Pese a la posible frialdad que puede trasladar la palabra objetual, tan alejada en principio de la organicidad de los elementos de la naturaleza, su uso nos permite aglutinar una serie de características muy rentables para nuestro estudio. En primer lugar, la unicidad de los poemas, adscritos por completo a una única realidad aislada de la naturaleza, motivo por el que la construcción poema objetual (resultado de la suma de esas dos nociones: poema y objeto) subraya la plena identificación entre composición y recreación de un objeto único de lo natural. En segundo lugar, la alusión que gravita en torno a la palabra objetual respecto a la objetivación de las realidades enfrentadas, algo que guarda mucha relación con el carácter demorado de las descripciones ofrecidas. Y, por último, la inconcreción antes referida de la misma palabra objetual, palabra que no nos sitúa en un principio en el seno de un entorno natural, lo que sería el mayor inconveniente para nuestro caso, pero que es lo suficientemente 
amplia como para funcionar con otros poemas objetuales, posteriores a los de los poemarios que estudiamos, en los que el objeto encarado ya no pertenece a la naturaleza, aunque los procedimientos estéticos empleados en la descripción se ajusten por completo al modelo de poema objetual que en lo sucesivo propondremos.

Hay dos antecedentes que con total seguridad podemos plantear que influyeron en la formulación de este tipo de poemas por parte de Velasco. Nos referimos a las odas elementales de Neruda y a algunos poemas de Claudio Rodríguez. La declarada admiración de Velasco por los dos poetas, más explicitada aún en el caso del poeta zamorano, avala tal afirmación ${ }^{8}$. Tanto el uno como el otro, desde presupuestos estéticos totalmente distintos, abordaron la naturaleza con propósito encomiástico y, sobre todo, alumbraron un modo de perfilar la realidad que centraba todos sus esfuerzos en la celebración del detalle, en la creación verbal de las cosas observadas transubstanciadas por medio de la lengua en materia poética. Este interés por cantar lo mínimo, tan evidente en muchas de las odas elementales de Neruda, es uno de los principales impulsos de la poética objetual de Velasco; así como la creación verbal de las cosas del Claudio Rodríguez de poemas como "Girasol», "Gorrión», «Espuma» o "Amarras» (auténticos prodigios de sensibilidad despierta y precisión metafórica, sobre todo en los dos últimos casos) se amolda muy bien también al patrón que nuestro poeta seguirá en sus composiciones del poema objetual. Por si fuera poco, esa «mirada sin dueño» claudiana que tanto persigue Velasco en sus poemas ${ }^{9}$, la cual marca por completo la percepción de los objetos que después nos devuelve, certifica tal conexión, si bien el medio para acceder a ella, el éxtasis lisérgico, es privativo del poeta mallorquín.

Esa «mirada sin dueño» de la que hablamos es el principal impulso que espolea la creación de los poemas objetuales. Una vez

8 En cuanto a la rendida admiración queVelasco le profesaba a Claudio Rodríguez, podemos citar las siguientes palabras, pronunciadas al poco de la muerte del poeta zamorano: «La lectura de Claudio Rodríguez, como la de García Calvo, fueron para un servidor casi las últimas experiencias de poesía viva en español contemporáneo, antes de que el mercado terminase de convertir a sus plumíferos en figuras decorativas desvividas por imponer su marca personal, en un gremio egotista, obediente y acrítico" (en Rodríguez Marcos, 2010). Puede mencionarse, asimismo, el artículo completo que le dedicó en Archipiélago, titulado «Oliendo a brea» (Velasco, 2004).

9 Ver nota 6. 
abierta la percepción del poeta por medio del consumo de alucinógenos, los objetos se aparecen ante él como vistos por primera vez, en un proceso de minuciosa observación que nos revela la posibilidad de asombro, de perpetuo asombro que esconden las cosas de nuestro vivir más cotidiano. A ese nuevo modo de ver y, al mismo tiempo, de descubrir los objetos Isabel Escudero lo ha llamado «esa curiosa visión no iluminada de frente, sino más bien al sesgo o desde atrás» (Escudero, 1997: 141), apreciación del todo acertada por cuanto comunica de forma sencilla el cambio de perspectiva que opera en estas poesías. En esta nueva contemplación, límpida y escorada, reveladora de los secretos que esconden las cosas bajo su asimilada apariencia, tendrá mucha importancia lo que podemos concretar en una fórmula tan simple como el acercamiento; es decir, el poeta aprende a observar las cosas desde otra óptica, desde otra perspectiva, tal y como dice Escudero, pero lo que fundamenta esta nueva visión es, sobre todo, el acercamiento a esas realidades, a las que Velasco se aproxima buscando cantar su humildad y, al mismo tiempo, la complejidad de su sencillez. Así lo expresa Carlos Marzal:

A menudo, en sus composiciones, la mirada se suele posar en la realidad con apetito de lupa, y desde allí se eleva hacia la reflexión y hacia el cántico. Una bandada de pájaros, el intrincado laberinto de unas hojas observadas con minuciosidad, una piña en el fuego, a punto de consumirse, un viejo retrato de familia, mil y un aspectos del universo material, sirven a veces para que el poeta ausculte la respiración secreta de la vida. Para que - llegamos a creer- descorra el velo que envuelve el misterioso cosmos (Marzal, 2011: 10-11)

Algunas de las realidades a las que se refiere Marzal en este fragmento integran el nutrido grupo de objetos de los poemas objetuales, como, por ejemplo, la «bandada de pájaros» («Las garzas» [Velasco, 2003: 81-82]) o la piña crepitante de «Piña de lumbre» que cita después. La fórmula seguida en los dos casos, extensible a todo el grupo, es la siguiente: el poeta nos ofrece la descripción fascinada de un objeto único de la naturaleza al que aísla y enfrenta desde una perspectiva laudatoria y con un gran caudal de recursos retóricos, los cuales, además de intensificar la realidad del objeto evocado, forman en conjunto una suerte de sinfonía afirmativa que canta la maravilla del mundo con agradecimiento y sensualidad en 
el lenguaje. Este intento por aislar las cosas y por contarlas bajo el prisma de la nueva mirada se manifiesta ya desde el principio en la constante combinación de título y cuerpo del texto que en estas composiciones aparece. Así, mientras que la mayoría de poemas objetuales presenta siempre un título inequívocamente alusivo al objeto protagonista (el nombre común del mismo, a veces acompañado de un artículo determinante y, otras, por el contrario, propuesto sin más, sin ningún complemento a su alrededor, cosa que consigue el efecto de recalcar el valor simbólico del objeto en cuestión), el desarrollo de la composición evita siempre mentarlo, gracias a lo cual se esquiva el estorbo que comportaría la referencialidad inmediata evocada por tal palabra. Tal nominación distraería al lector del discurrir deslumbrado del poeta, fundamentalmente por romper con el lenguaje metafórico-simbólico que a este acompaña. Así pues, título y cuerpo del texto trabajan en una misma dirección: la re-construcción poética de una realidad dada, explícita ya en el título, que, mediada por metáforas, sinestesias y otros recursos de diversa índole, se transforma en otra realidad distinta, siempre resultante del enfoque extático que en el poeta propicia la mirada ebria.Título y desarrollo, pues, objeto concreto o realidad apelada y reconstrucción metafórico-poética, son los dos elementos estructurales de este tipo de poemas.

Por otro lado, una de las señas de identidad del poema objetual es la leve sensación de tiempo ralentizado que lleva aparejada. Tal impresión temporal se debe a varias razones: la desconexión con el resto de la realidad, sobre todo aquella más lejana a la naturaleza, el arrobo del poeta ante el objeto descrito y, principalmente, la morosidad con que este se detiene en el esbozo de sus cualidades. De esta manera, muchos de estos textos se presentan casi como si fueran ajenos al devenir natural del tiempo, un efecto que consigue contagiarnos la obnubilación que presumiblemente embarga al poeta en el trance de su observación natural.Y lo hace sobre todo por una razón: la habilidad de Velasco al sortear el carácter pautado y, digamos, de aliento enumerativo de la descripción prototípica, sustituyéndolo por la superposición de ideas poéticas originales — casi ráfagas de luz, muchas veces en forma de distintas metáforas visuales- que transmiten el reposado mirar del poeta, los distintos centelleos que se desprenden de su detención extasiada ante el hecho natural. Muy ilustrativa en este sentido puede resultar la composición «Piña de lumbre»: 
El fuego laborioso hace de oro sus escamas tupidas, y ya es una rosa de ascua.

La socavan las llamas impacientes, la acometen sus lenguas codiciosas, y cede aquí, de su tesoro, espléndida, un pétalo de plata.

Se deshoja despacio, se va abriendo con tiempo a esa primavera de su quiebra. Y cuando se diría que fuese a derrumbarse, porque cruje la prieta arquitectura, sobrelleva el embate, aunque ya es una rosa apurada.

Luego un pequeño roce bastará. Una lengua muy fina hallará paso hasta su recoveco y, apenas con soplar, romperá el sello de su cámara íntima.Y entonces se desmoronará de golpe, súbita, la estructura completa. Pero ve cómo resiste aún la vieja ruina, ese abrasado corazón, tan tuyo, porque es ceniza, y arde (ibíd.: 55).

La repetición incesante de verbos («hace», «socavan», «acometen", «cede») que describen la acción del fuego sobre la piña y su consecuente degradación produce el efecto temporal mencionado, trasladando una sensación de acciones encadenadas, de sucesión temporal, a lo que únicamente es un conjunto de metaforizaciones sobre el efecto del fuego en el fruto. Con idéntico resultado, se demora la descripción con diversas alusiones al tiempo («Se deshoja despacio, / se va abriendo con tiempo / a esa primavera de su quiebra»), las cuales destacan el lento consumirse de la piña, a lo que se une más tarde el efecto suspensivo de los versos 11-15, donde el fruto parece a punto de explotar pero... «sobrelleva el embate». Tras esto, se cede un instante el hilo discursivo al momento futuro en el que, de súbito, se acabará venciendo la piña por el fuego, para finalmente volver en los últimos cuatro versos al momento presente anterior, en el que concluye el poema con la piña, aún entera, 
resistiendo la acometida del fuego. Todo el proceso, pues, abunda en la dilatación del tiempo.

Algo muy distinto ocurre en «La telaraña». La descripción del efecto lumínico del sol al amanecer sobre la telaraña, tornasolando los hilos de que se compone, descansa sobre un encadenamiento de formas verbales ("desciende íntima», en personificación de los primeros rayos del sol del amanecer; «descubre», «tiembla», «se ensartan» e, incluso, "hace su música») que impone una sucesión temporal al hecho del amanecer, pero lo hace, en este caso, condensando todo ese proceso en unos pocos versos:

\author{
La caricia del sol desciende íntima \\ sobre la yerba húmeda y descubre \\ la delicada urdimbre: su oro tiembla \\ como jirón de sueño todavía \\ prendido a la mañana. \\ Por sus hilos se ensartan irisadas \\ las cuentas del rocío. En esas cuerdas \\ el bosque hace su música más límpida, \\ mientras la vida se nos queda presa \\ en el arco iris de la telaraña (Velasco, 1998: 44).
}

Así pues, aunque el resultado en este caso es el contrario al de la tónica dominante de estos poemas, pues el tiempo en vez de dilatarse se condensa, la impresión de tiempo subrayado, intensificado es similar. El poeta, hábilmente, consigue manejar la temporalidad interna de sus composiciones para, en primer término, dotarlas de un ritmo particular, dado por el efecto de sucesión temporal que los verbos encadenados imponen, y, en segundo término, alargar o retardar su avance en pos de la delectación del lector, ya sea con objeto de mostrarnos con lentitud exacerbada el deterioro de la piña en la lumbre, ya sea con la finalidad de reafirmar el carácter revelador de la luz del amanecer, como sucede en este último caso.

Otro de los rasgos característicos del poema objetual es la sensorialidad. Miguel Ángel Velasco es un poeta de claro instinto sensorial, lo que no significa que su poesía no sea también hondamente reflexiva, llegando muchas veces a las lindes de lo metafísico. Echando la vista atrás hasta sus inicios para seguir el correr de su trayectoria, queda claro que su intención estética o estetizante está frecuentemente puesta al servicio de la experiencia de los sentidos, sacando de ello en beneficio un magistral uso de diversos recursos 
retóricos sobre los que queda cifrada su percepción gozosa, casi hedonista, de los dones del mundo, algo que se aguza sobremanera cuando la lente del entusiasmo lisérgico se interpone entre poeta y objetos. Recursos como la metáfora (casi siempre visual) o la sinestesia demuestran la creativa, apasionada y en ocasiones abigarrada forma de sentir el mundo del poeta mallorquín. Y aunque sentidos como el tacto o el oído (en muchas metáforas referidas al sonido del viento, por ejemplo) también tienen su importancia en los poemas naturales de Velasco, lo cierto es que el predominio del sentido de la vista es indudable, y más en sus poemas objetuales, en los que, en caso de aparecer otro sentido, suele vincularse al de la vista por medio de la sinestesia. Esta hegemonía de lo visual se hace más que razonable en estos poemas objetuales porque su propósito descriptivo, de acuerdo con la descripción prototípica de realidades corpóreas, que siempre da mayor peso a la información visual, requiere de tal preeminencia, cosa que, por otro lado, no pueden menos que acentuar los fenómenos alucinatorios de tipo visual inherentes a la mirada ebria del poeta. Y precisamente esa mirada ebria («ebrio del mundo») es la que da inicio al poema con que queremos ejemplificar esto, «Lombardas», del que nos interesa sobre todo su exuberante sensorialidad visual en lo que toca al cromatismo, que hace de él una composición repleta de colores y materias asociadas a estos. Marcamos con versalita todos los ejemplos significativos a este respecto:

Ebrio iba del mundo cuando vi aquellas coles rizándose de PLATA como ESPUMA del surco. Diríase que públicas al par que pudorosas, absortas en su pompa de corolas atroces.

Tan pronto raso AÑIL como seda VIOLETA o copiando del cielo el ZAFiro más puro las coles se IRISABAn como si las bruñese el TORNASOL profundo de una ROSA secreta.

La savia dibujaba con pincel minucioso en las sedas AZULES filigrana ESCARLATA. Honda lumbre encendía las coles cristalinas de ROSA MADREPERLA cual lámparas sagradas.

Al punto la madeja delicada de hojas se henchía sudorosa de una savia más viva 
y aquellas hortalizas parecían de pronto el sueño vigilante de grandes MARIPOSAS.

Largo tiempo el que estuve asomado a la huerta pues todo se entendía junto a aquella VERDURA.

Eran la misma cosa su rica nervadura que las venas AZULES de mi mano en la cerca.

Y cuando me alejaba de las coles, sabiendo que mi vida más cierta se quedaba con ellas, vi en sus hojas alzarse como enaguas y alas de novicias y ángeles remontándose al cielo (ibíd.: 41-42).

Citábamos líneas atrás un texto de Carlos Marzal en el que se refería, entre otras cosas, al «apetito de lupa» de la mirada deVelasco, expresión muy adecuada por cuanto pone de manifiesto la querencia de nuestro poeta por las pequeñas cosas del mundo y, especialmente, en el caso de los poemas objetuales, por aquellas realidades de la naturaleza sobre las que con frecuencia pasa nuestra mirada sin reparar apenas en su belleza. Este canto a los objetos más humildes de la naturaleza no es, ciertamente, un aspecto que tengamos que considerar indispensable; principalmente porque alguno de los poemas objetuales que podríamos sugerir escapan a tal consideración, como es el caso de «El arco iris sobre el camposanto» (ibíd.: 49-50), en el que se describe una realidad natural de enormes magnitudes, o, de modo quizá menos conflictivo, «El cerezo» (ibíd.: 47-48) y «Viña» (ibíd.: 43), que no parecen tampoco insertarse en ese ideal de menudencia. Con todo, la fuerza motriz que empuja estos tres poemas es igual a la de los otros: la alabanza de corte embellecedor y estetizante de distintas entidades de lo natural que, de mayor o menor tamaño, aunque frecuentemente de medida reducida, pasan inadvertidas a la mirada común y distraída del ser humano, casi como si se tratase de detalles insignificantes. Es, pues, la noción de detalle (aparente detalle ignorado), incluso en algo tan mayúsculo como el arco iris, lo que une todas estas composiciones. En cualquier caso, la mayoría de ellas sigue el patrón del sujeto poético que focaliza su atención en lo pequeño, en un proceso al que Isabel Escudero se ha referido como el «propósito [...] de decir el milagro de lo mínimo» (1997: 141), propósito que, por otra parte, 
sanciona toda una tradición literaria de elogio de la belleza mínima natural ${ }^{10}$.

Uno de los poemas objetuales en el que con más claridad se observa todo esto es «El escarabajo» (Velasco, 1998: 45). En él, el sujeto poético centra su mirada en el objeto-sujeto mínimo de un escarabajo, el cual transporta con dificultades un bulto. La carga manifiestamente negativa de los adjetivos con los que se describe este proceso ("terco afán», «miserable carga» e, incluso, «camino tórrido»), unida a la imagen de patetismo en la que el escarabajo, volteado, trata de recuperar su posición moviendo las patas de un lado a otro, termina cuando la compasión del sujeto poético cede ante la reverencia a la que da paso la belleza del escarabajo reflejando el brillo del sol sobre su coraza, en un proceso de dignificación del insecto que trueca el «vasallo esforzado» del segundo verso en el «monarca» —y, para más inri, «indiferente»— del penúltimo. De este modo, nos interesa «El escarabajo» porque en él tiene lugar ese proceso de dignificación de lo pequeño que alcanzará a muchos de los poemas del autor sobre la naturaleza, siendo parte protagonista especialmente de aquellos que hemos llamado poemas objetuales. Con todo, la mayor parte de estos poemas no siguen exactamente este patrón, pues parten ya de una afianzada conciencia del valor de lo ínfimo natural y de sus potencialidades.

El último tramo del viaje de conocimiento que supone la práctica lisérgica en Velasco comienza a darse sobre todo a partir de

10 Sin ir más lejos, dentro del ámbito de la literatura española, el dominico fray Luis de Granada dedicó un capítulo al tema en su Introducción del Símbolo de la Fe, bajo el título «Cómo resplandece más la sabiduría y providencia del criador en las cosas pequeñas que en las grandes». La idea, puesta, claro está, al servicio de la teleología natural que se propone trazar Luis de Granada, contaba ya con una firme ascendencia, de la que buena cuenta dan las autoridades a las que recurre el dominico en el texto: san Jerónimo, san Agustín, Hugo de san Víctor, etc. Interesa esta referencia, no solo por la tradición en la que se engarzan los poemas de Velasco, elementos religiosos aparte, sino también porque tenemos la certeza de que Velasco fue lector de la obra, como demuestra el poema «El símbolo de la fe» (2009), publicado póstumamente en La muerte una vez más (Velasco, 2012: 241). Desprovisto, como decimos, de todo elemento religioso, Velasco también confía en la elocuencia de los objetos pequeños para comunicar la belleza del mundo. Y aunque su lectura de la naturaleza no pretenda, como en el caso de Luis de Granada, rastrear las huellas de Dios en lo natural, algunos elementos permiten emparentar a los dos escritores, tales como la expresión afirmativa y enaltecedora del mundo, por un lado, o la espaciosidad y el detallismo de las descripciones, por otro. 
La miel salvaje, si bien es cierto que ya puede intuirse en algunas composiciones del El dibujo de la savia. El principal rasgo que distancia algunos de los poemas naturales de La miel salvaje de la gran mayoría de los de El dibujo de la savia es la búsqueda o, por mejor decir, el encuentro y confirmación del sentido de la realidad y, en especial, de la naturaleza al que Velasco llega por el estado de especial lucidez al que le transportan los alucinógenos. Como ya hemos explicado, una de las características inherentes al consumo de estas substancias es la sensación de verdad que las acompaña, conducente en muchas ocasiones a una fuerte impresión de revelación. A partir de esta revelación, entendida como un estado de comprensión absoluta del mundo, de comunicación total con este (a veces llegando a planteamientos panteístas), el poeta consigue reflejar por medio de las palabras las conclusiones que le depara la experiencia lisérgica, que si no pretenden una explicación totalista del mundo, sí vehiculan un sentir de la realidad como un complejo conjunto de símbolos y simetrías, de reflejos y contrarreflejos, de uniones insospechadas y conexiones ocultas, de correspondencias, en suma, que recalcan la organicidad, la unión inteligente e interdependiente de la existencia. Esta última idea viene dada por un proceso de penetración en la realidad, de busca tenaz del conocimiento de las cosas. Por lo tanto, el salto temático con respecto a los poemas objetuales de El dibujo de la savia es evidente. Ya no estamos ante la mera alabanza de las cosas aisladas que allí sucedía, cosas que, sin duda, conformaban un canto afirmativo de las dádivas de la naturaleza, de sus pequeños y embellecidos milagros, pero siempre y cuando nosotros nos encargásemos de hilarlas artificiosamente, atendiendo a sus evidentes concomitancias pero admitiendo también la independencia de cada texto. En este caso, sin embargo, aunque los textos siguen siendo autónomos, el propósito común que los informa se hace evidente. El poeta no solo se muestra admirado de la naturaleza observada; también, después de haber dedicado largo tiempo a pensarla, a meditarla con delectación, nos regala el hallazgo imponente de sus pesquisas: la unicidad de la creación o, en otras palabras, la existencia de lo que llamaremos las correspondencias.

El primer paso que encamina a Velasco hacia este orden cósmico revelado tiene lugar en la ya referida valorización de lo pequeño de algunos poemas de El dibujo de la savia. Comentábamos antes la propensión del poeta a celebrar la belleza de lo pequeño, deteniéndonos en «El escarabajo». Muy similar estimación de las 
pequeñas cosas se despliega en la segunda parte de "La alegría», siendo aún más importante si cabe que el ejemplo del escarabajo, pues del catálogo de objetos de reducido tamaño que se nos da se destaca su capacidad comunicativa, conceptuada como una forma de entendimiento, algo que nos va acercando un poco hacia donde nos dirigimos:

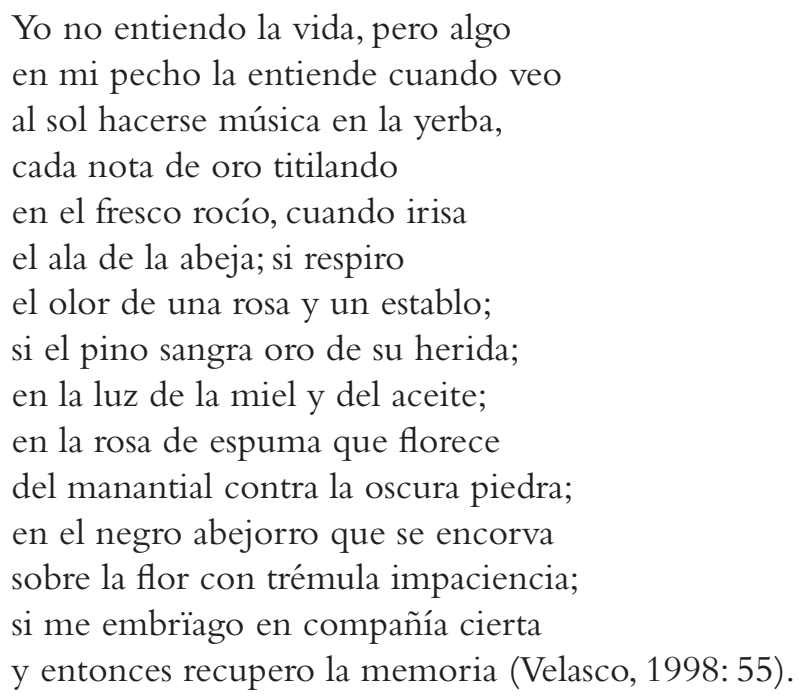

La afirmación del poeta no puede ser más clara: considera el goce de las pequeñas realidades de la naturaleza como una fuente de conocimiento, que le permite comprender de otra manera la vida y, al mismo tiempo, recuperar la memoria, referencia que conecta con la «memoria de las cosas» de otro poema del mismo conjunto, «La noche de la materia» (ibíd.: 23-25). Así pues, este primer grado de conocimiento que la naturaleza diminuta le ofrece no debe pasarse por alto, tan supeditado, por lo demás, a la impresión de revelación antes dicha. Por otro lado, en parejo sentido habríamos de interpretar los versos de la penúltima estrofa de «Lombardas», donde el poeta apela una vez más al conocimiento que le traslada la realidad natural: «Largo tiempo el que estuve asomado a la huerta / pues todo se entendía junto a aquella verdura» (ibíd.: 42). La impresión de revelación que sacude al poeta se sostiene en el valor pasivo reflejo del «se» utilizado (las cosas son entendidas por el poeta); en caso de tratarse de un «se» reflexivo (las cosas se entienden entre sí), la interpretación seguiría sirviéndonos, pues conectaría con otra idea que sugieren algunos de estos poemas: el panteísmo. 
Pero este primer grado de conocimiento no se detiene ahí. En seguida comienza a avanzar en una misma dirección, la de emparentar lo minúsculo descrito con lo mayúsculo abarcador, un viaje que se concretará en una constante a la que nos vamos a referir como lo uno inmenso en lo otro diminuto. El fragmento siguiente, extraído de «Lázaro», es uno de los primeros en los que se relacionan lo pequeño y lo grande, esta vez con el propósito único de poner de relieve lo primero, aunque dentro del mismo poema también encontremos ejemplos de lo uno en lo otro: «el zarcillo y su rúbrica menuda, / no menos soberana que el oleaje / del encinar» (ibíd.: $26)^{11}$.

La idea de lo uno inmenso en lo otro diminuto, deudora hasta cierto punto de las relaciones de macrocosmos y microcosmos del neoplatonismo, conlleva un relevante acercamiento a la poética de correspondencias que se irá desarrollando en otros poemas. A partir del interés que tiene el poeta en realzar las cosas inapreciables que constituyen la naturaleza, nace la intención de este de poner de manifiesto la conexión de orden cósmico de materias diminutas y materias enormes o envolventes. Un buen ejemplo de este proceso lo tenemos en «Primera primavera», donde el poeta, atravesado por el dolor de la muerte del padre («después de que mi padre / haya dejado, al alejarse, abierta / esa puerta que da a la ciega noche»), describe una "flor menuda» en la que, al final del desarrollo, en su «breve corola», llega a ver el «hondo cielo»: "y me agacho, / y pongo mi ojo al ras de tus estambres, / y allí veo, asomándome a lo íntimo / de tu breve corola, el hondo cielo / de esta primera primavera» (ibíd.: 37-38). Con idéntica significación funcionan estos otros dos ejemplos, aludidos en el párrafo anterior, extraídos los dos de "Lázaro»: "cada gota / en que se copia entera la mañana», por un lado, y «toda / la noche cabe en una rosa blanca» (ibíd.: 26), por otro, ejemplo este último que intensifica la disparidad de las magnitudes relacionadas gracias a la también disparidad cromática de la pareja «noche»-«rosa blanca».

11 Sobre esta insistencia de Velasco en unir objetos de magnitudes distantes, José Saborit ha dicho lo siguiente: «de él aprendí la singularidad de una mirada atenta por igual a lo pequeño y a lo grande, a lo cercano y a lo lejano. Juntos miramos el preciso baile de la araña, el oro en la resina del pino, la minucia vegetal, las brasas, el amonite.Y juntos nos perdimos por las lejanías del horizonte y del cielo, tras las veleidosas nubes, por las escarpaduras del gigante de basalto que se divisaba desde la terraza de su casa» (Saborit, 2011:21). 
Esta inclusión de nociones inabarcables (la mañana, la noche) en objetos mínimos no viene solamente a subrayar el carácter simbólico y aglutinador de estas pequeñas realidades; tiene sobre todo la intención de representar la mirada abarcadora del poeta, que poco a poco va tomando conciencia de la unicidad del mundo y de las correspondencias tejidas en él. De modo que son dos los objetivos que animan estos fragmentos: por un lado, cantar la dignificación de lo pequeño, réplica a escala de las potencias mayores del universo que provoca un denodado elogio de lo diminuto; y, por otro, establecer ya, a cuenta del relativismo invocado, una concepción transcendente del mundo y sus simetrías como un todo interconectado, donde lo minúsculo y lo mayúsculo urden un tejido invisible de correspondencias que da cuenta del orden cósmico de la realidad. Estos ejemplos, pues, podrían considerarse un primer paso en la poética de las correspondencias, algo que además encuentra apoyatura teórica en nombres como Isabel Escudero (1997: 141) o Vicente Gallego (2008: 13), que ya hicieron notar semejante fenómeno. Un ejemplo posterior a los que hemos analizado en estas líneas lo podemos encontrar en La vida desatada. Se titula «Una pluma» (Velasco, 2000: 55-56) y contiene unos fragmentos muy ligados a este tema, en los que el poeta traduce la cualidad sintética de dicha pluma («en ella estaba el pulso / de la mañana intacto, ese latido / pudoroso de un día como tantos: / en ella estaba el cielo encapotado, / también de un gris de plomo, / y el bullicioso encaje de la espuma»), a lo que después se agrega el elemento sentimental ( $\mathrm{Y}$ los ojos de acero / de una mujer que habías deseado. / Se redimía el mundo en esa pluma / caída entre la yerba, junto a un cardo, / unas cansinas malvas sin aroma / y un ágave gastado»), buen ejemplo este con que demostrar las implicaciones transcendentales que despiertan los objetos en Velasco.

Así pues, la búsqueda del conocimiento de Velasco sigue el siguiente trazado: de lo pequeño puesto en valor se pasa al entendimiento lúcido de las simetrías entre lo pequeño y lo inmenso, para, poco después, condensarlo todo bajo el concepto nuclear y recurrente de las correspondencias. Esta poética de las correspondencias, que remite muy ligeramente a las correspondencias baudelarianas, se puede explicar apelando a una de las características prominentes en la estética de Velasco: la tendencia a la creación de asociaciones insólitas, algo de lo que dan buena cuenta los ejemplos de metáforas, sinestesias y, aún más si cabe, comparaciones creativas 
que presenta toda su obra. Sin embargo, la lectura de este fenómeno no puede reducirse a un planteamiento únicamente estético, pues mucho más significativo que ello es el orden cósmico intuido del que nos informan.

Sobre la poética de las correspondencias contamos con un testimonio del propio Velasco recogido en una entrevista. Se trata de un documento muy útil, pues en él se reconoce la importancia de este fenómeno para explicar las claves de sus últimos poemarios. Aunque las declaraciones se refieren a Fuego de rueda, que queda fuera del radio de este trabajo, el mismo Velasco reconoce que esta manera de poetizar solo es una continuación de La miel salvaje:

- ¿Podrías hablarnos de Fuego de rueda?

- Fuego de rueda es una extensión del territorio que en $\mathrm{La}$ miel salvaje se configuraba en torno a una voluntad abarcadora: la vida de las formas, los patrones de crecimiento, los fenómenos de transculturación de determinados troqueles simbólicos, hasta formar una greca o fresco que tiene su continuación en este último libro [...]. Si tuviese que ponerme bajo la advocación de una patrona la llamaría curiosidad, una gran curiosidad.

- ¿Podrías hablarnos de tu concepción de la poesía?

- La que intento hacer es una, podríamos llamarla, poesía de la atención. Partiendo de un objeto dado, ver cómo este se corresponde estructuralmente con formaciones análogas de otros ámbitos, entregarme a su capacidad evocadora, indagar en esa trama de las correspondencias (en San Miguel: 2012).

Rotunda confirmación de estas palabras es el poema «Correspondencias», auténtico poema-poética:

Los ojos se nos van tras el diverso acopio con que la vida vuelca su Cuerno de Abundancia: una criatura imita la corteza del árbol; otra, meticulosa, se adelgaza en espina; la efimera aparenta ser una estricta flor, y la sierpe se emboza en la piel de la arena. Todo quiere volver a su vieja morada: el lagarto a la piedra y el insecto a la hoja. Más allá de defensas, por encima de astucias, todo asiente, entregado a una oscura obediencia. 
Trae el viento en su alforja cosecha de los mares

y labra en el desierto sus espaciosas ondas, y las olas esculpen con secular paciencia en la falda del monte su ola innumerable.

Todo es un solo pulso en su vida profunda.

Todo tiene memoria de una antigua heredad.

Y al mirar tanta ciencia como llega a mi vista, su caudal va creciendo, cuerpo adentro, en mi fondo:

el minucioso polen, la luz de la alborada, el manto de los astros, las manchas del jaguar... ¿Conoceré algún día la restallante fórmula?

Acaso en esa noche vigilante del párpado la veré en un destello, por la puerta entreabierta, toda mi vida junta en apretada rosa, a un tiempo detenida y a un tiempo presurosa, con centro en todas partes y contorno en ninguna. Y al fin bajaré a vueltas con esa rueda honda, abarcándola toda, en una ojeada limpia, como en un libro abierto, la concisa escritura en una sola hoja que es otra y otra y otra... Y en la urdida cadencia de la estrofa sin tiempo, ganando las escalas de su música íntima, despertará mi vida al sueño de las cosas (Velasco, 2003: 51-52).

El mecanismo utilizado es siempre el mismo: la conexión de distintas nociones de la naturaleza (la criatura que se esconde en el árbol, las olas del mar y las ondas del desierto) con las que se trata de reafirmar ese "solo pulso» (panteísmo) que vertebra lo real, en un proceso de búsqueda de la «restallante fórmula» —esto es, del conocimiento último de la existencia- que guía las aspiraciones del poeta ${ }^{12}$. Esta forma de comprender la realidad enlaza con

12 Sobre esta poética de las correspondencias se han realizado distintas consideraciones. José Luis García Martín, por ejemplo, la explicaba así: «Son poemas en los que el autor contempla la realidad más cotidiana y sabe ver en ella su andamiaje secreto, las misteriosas correspondencias que unen el grano de arena y las galaxias» (García Martín, 2003). También son interesantes las palabras que le dedica Francisco Díaz de Castro al tema: «Y también a la belleza otra que ofrecen a la relajación mística de la mirada las simetrías de los mandalas, los fractales, el erizo, las figuras espirales del cosmos y del arte, el sistema de símbolos distinto que, mediante la ensoñación inducida, establece otras formas de correspondencias entre todas las cosas» (Díaz de Castro, 2011: 52). Y las de Vicente Gallego: «en otras ocasiones el universo se manifiesta transfigurado en una extensa red de 
la tradición psicodélica de la que bebe Velasco, que tiene especial propensión a literaturizar sus experiencias alucinatorias. En este sentido, las palabras que Velasco escribió sobre el escritor y filósofo Ernst Jünger, reconocido consumidor de substancias alteradoras de la conciencia, resultan más que pertinentes por lo que toca a este asunto:

Desde la filigrana de botánico a la metáfora cristalográfica, pasando por el pormenor entomológico, Ernst Jünger apenas tiene parangón en las letras contemporáneas como forjador de imágenes tomadas de la naturaleza; y así como en ocasiones su mirada atenta descubre esquirlas de infinito en los fósiles, delineando desde el pequeño fragmento, con vigoroso trazo, un fresco telúrico, o ve el trabajo de las olas en el tornasol de un ala o busca descifrar textos en los élitros de los insectos, es en la contemplación del reino vegetal donde lleva a cabo su más acendrada elaboración poética, exaltación de un ámbito sosegado en el que el autor alemán ve el trasunto de las ideas, discurrir íntimo de la savia desde el que fundar aspiraciones de absoluto y del que deducir imágenes de perennidad, en una suerte de botánica teológica (Velasco, 1995: 101).

También lo son algunos versos del poema dedicado al padre del LSD, titulado con su mismo nombre: «Albert Hofmann». En él se insiste en el carácter revelador de la experiencia enteogénica («vio las cosas $[\ldots]$ como por vez primera»), así como en la representación panteísta del universo como un todo armonioso que vivificaría «una misma savia audaz». Por otro lado, y esto es lo que más interesa ahora, algunas de las imágenes de lo uno inmenso en lo otro diminuto de Velasco descubren su autoría en el científico suizo (el rodar del mar en las conchas, la corola de una flor como símbolo del cielo, las púas del erizo y los astros), por lo que la tradición psicodélica de la que hablamos se pone de manifiesto:

$$
\begin{aligned}
& \text { disciplinó su vista y vio las cosas } \\
& \text { al punto definidas, como por vez primera: } \\
& \text { esa aurora del polen, } \\
& \text { el oro erguido de la prieta espiga, }
\end{aligned}
$$

correspondencias cuyos íntimos nudos han sido atados por el gozo», a lo que después añade: «le ha encontrado un sentido a este gran rompecabezas cósmico» (Gallego, 2008: 22, 24). 
un cielo minucioso en las corolas

y en la concha el rodar de las mareas.

Y en todas vio una misma savia audaz:

en la dura corteza y en la oruga,

en la rosa mojada y la babosa.

Conoció del erizo de mar y de los astros

la augusta simetría.

Supo la piedra en el talón de Aquiles

y la velocidad de la tortuga

(Velasco, 2003: 40).

Todo este intento por apresar la esencia de la realidad llevará a nuestro poeta a una honda indagación en los misterios de la geometría, indagación por la que también establece todo tipo de correspondencias que sancionan su visión de la realidad como un conjunto bien trabado de relaciones transcendentes, en este caso, de tipo geométrico. Así ocurre con poemas como "Ammonites» (ibíd.: 61-62) o «Espirales»: el primero, partiendo de la fórmula del poema objetual para después alzar el vuelo hasta el terreno de la abstracción geométrica, a lo que García Martín se ha referido como "el enigma del círculo» (García Martín, 2003); el segundo, llevando a cabo lo propio pero a partir ya de la misma abstracción geométrica, la forma de la espiral, de la que se buscan todo tipo de representaciones dadas en la realidad. A continuación, ofrecemos algunos versos de «Espirales» que muestran el procedimiento explicado, conectando la forma de la espiral con realizaciones tan disímiles entre sí como la cóclea del oído o la escalera de Jacob:

Espiral es la forma del soplo del espíritu, su resonancia clara cuando llega

al laberinto franco del oído.

Sois la torre del sabio, la escalera

resuelta de los ángeles.

Ese rizo en la barba venerable

del dios de la abundancia,

el alfarero insigne que propaga

desde la orilla de la aurora abierta

su consonancia sideral de ondas.

Sois, torbellino adentro, los tumultos

de nuestra propia sangre, y sois, al tiempo,

ese flagelo íntimo enroscado

en la burbuja tóxica. 
El cuerno retorcido en la defensa.

La barrena tenaz de la carcoma.

Y el tifón sois, su remolino ciego,

presurosa corola que recoge

de nuevo en torno al eje de su fuga

la amarra de su vértigo

(Velasco, 2003: 79-80).

Otras veces las relaciones entre cosas no se centran en entidades geométricas, sino en otro tipo de recurrencias capaces de excitar el proceso poético de las correspondencias. Es el caso de «Mariposa manchada", donde son las manchas de una mariposa las que suscitan tal proceso:

Todo está inscrito en el menudo pliego

de esos pétalos tenues

que en su prisa retratan este mundo

mientras su vuelo se deshace en polen:

ojos multiplicados, anacondas,

caparazones, prímulas, panales.

Las máculas del sol y la viruela

de la luna. Las llagas del martirio.

Las limpias nubes misericordiosas.

Gotas de sangre. El jaspe de los templos.

Estigmas y denarios y cadenas.

La roja herrumbre y las salpicaduras

del barro en la diáspora.

Los cardenales en la piel del tiempo...

Las consteladas alas que no sienten

el peso de leopardos y legiones (ibíd.: 73).

Pero todas las composiciones de este tipo responden siempre a un mismo propósito: revelar la secreta urdimbre de las cosas y su sistematizada disposición, el orden cósmico que subyace en la realidad. Términos como "arquitectura», "ritmo», «equilibrio», «danza precisa», «orden» o "concertado pulso», todos ellos integrantes del poema titulado "El humo del cigarro», así lo confirman. Se trata, pues, en este poema, de divagar sobre la fórmula que rige el en apariencia caprichoso trazo del humo, el cual se comunica después, en uso de la poética de las correspondencias, con la rotación de las nebulosas o el latido de los mares: 
Miras a contraluz el suelto hilo que se devana en fáciles volutas. $\mathrm{Y}$ en esa transparente arquitectura reconoces un ritmo, el equilibrio de una danza precisa.

Y te dices que el humo tiene un orden, un concertado pulso que edifica su liviana columna.

El mismo que gobierna la rotación de antiguas nebulosas, el latido puntual de las mareas y el de tu corazón, desafiando el peso de la tierra (ibíd.: 37).

Finalmente, muchos de estos ejemplos podrían relacionarse con uno de los ingredientes típicos de la experiencia lisérgica: el fractal. El fractal (término también geométrico), aquella estructura que se contiene a sí misma hasta el infinito, en una sucesión de réplicas insertas que nunca llega a acabar, constituye una de las mayores obsesiones de los amantes del viaje lisérgico, sea dado por la visión alucinatoria, o sea descubierto en la realidad natural gracias al aguzamiento de sentidos característico de ese estado. De modo que al hablar de fractales no hablamos de una noción quimérica; al contrario, se trata de una realidad objetivable. En este sentido, no podemos concluir sin mencionarlos, pues añaden información imprescindible para la comprensión de las correspondencias, en especial para aquellas que hemos llamado lo uno inmenso en lo otro diminuto. «Fractal», poema dedicado a este fenómeno, formulado a partir de un lenguaje fuertemente irracional (motivado por la experiencia lisérgica), nos regala una descripción enfervorizada de la experiencia psicodélica en relación con este tipo de formas recurrentes. Sirva, pues, la definición de fractal que da el poema como cierre de este trabajo: «Era una fiebre blanca de puntillas, / un desflecarse el mundo en una fuga / de escalas sin motivo / en abanico roto de infinito» (ibíd.: 45). 


\section{BIBLIOGRAFÍA}

Díaz de Castro, Francisco J. (1984). «La realidad y el sueño», en Miguel Velasco, Palma, Universitat de Palma de Mallorca, s. p.

- (2011). «Tradición clásica y culturalismo en la poesía de Miguel Ángel Velasco", en Versos robados. Tradición clásica e intertextualidad en la lírica posmoderna peninsular, eds. Almudena del Olmo Iturriarte y Francisco J. Díaz de Castro, Sevilla, Renacimiento, pp. 29-62.

EsCudero, Isabel (1997). «Itinerario del éxtasis. El dibujo de la savia o de la orfebrería del alma», Archipiélago. Cuadernos de Crítica de la Cultura, 38, pp. 141-142.

Gallego,Vicente (2008). «Una ética del exceso. La poesía de Miguel Ángel Velasco», prólogo a Miguel Ángel Velasco, La mirada sin dueño, Sevilla, Renacimiento, pp. 11-24.

García Martín, José Luis (2003). «La miel salvaje», suplemento «El Cultural», El Mundo, 10 de abril. http://www.elcultural.com/revista/letras/La-miel-salvaje/6806 Legorburu, Javier (2011). «Velasco, 1981», La bolsa de pipas [«Velasco. Homenaje»], 80, pp. 12-18.

Llop, José Carlos (2010). "Pavana para un joven difunto», Diario de Mallorca. http:// www.diariodemallorca.es/opinion/2010/10/05/pavana-poetadifunto/60839 4.html Marzal, Carlos (2011). «Velasco elegíaco», La bolsa de pipas [«Velasco. Homenaje»], 80, pp. 10-11.

Prieto de Paula, Ángel L. (2008). «Otras corrientes líricas en los años ochenta y noventa», Biblioteca Virtual Miguel de Cervantes. http://www.cervantesvirtual.com/ portales/poesia_espanola_contemporanea/historia_otras_corrientes_80/

Rodríguez Marcos, Javier (2010). «Un milagro llamado Claudio Rodríguez», suplemento «Babelia», El País, 14 de agosto. http://elpais. com/diario/2010/08/14/babelia/1281744747_850215.html

SABorit, José (2011). «Gracias a Miguel Ángel», La bolsa de pipas [«Velasco. Homenaje»], 80, p. 21.

San Miguel, Enric G. de (2012). «Dos años sin Miguel Ángel Velasco», Diario de Mallorca. http://www.diaridemallorca.es/blogs/hati-hati/dos-anos-sin-miguel angelvelasco.html Sebastián, Andrés (1981). «Miguel Velasco: Un mallorquín que escribe en castellano", $A B C, 19$ de diciembre, p. 27. http://hemeroteca.abc.es/nav/ Navigate.exe/hemeroteca/madrid/abc/1981/12/19/035.html

Velasco, Miguel Ángel (1993). «La mirada sin dueño», Archipiélago.

Cuadernos de Crítica de la Cultura, 15, pp. 117-120. 
- (1995). «El dibujo de la savia», Archipiélago. Cuadernos

de Crítica de la Cultura, 20, pp.101-103.

- (1998). El dibujo de la savia, Zamora, Lucina.

- (2000). La vida desatada,Valencia, Pre-Textos.

— (2003). La miel salvaje, Madrid,Visor.

— (2004). «Oliendo a brea», Archipiélago. Cuadernos de Crítica de la Cultura, 63, pp. 43-45.

- (2012). La muerte una vez más, Barcelona, Tusquets. 